\title{
Study on the Durability of Concrete Lining by Using Early-Strength Agent
}

\author{
T. Yokoyama, Y. Uno, S. Hashimoto, and S. Date
}

\begin{abstract}
The purpose of this study is to verify the effect of the new concept of admixture (early strength agent). Its admixture was developed to achieve rapid construction. Original use of the admixture is to improve the productivity of a concrete secondary product. However, since lining concrete to carry out the demolding a relatively small strength, the authors were judged to be able to exploit the characteristics of the admixture. Then, pursuing the possibility of realizing the shortening of the construction period, is applied to the tunnel construction by NATM, it was measured such as compression strength and air permeability coefficient as the physical properties of the hardened concrete. In this paper, we describe the results of a study regarding the possibility of improving the durability in addition to the improvement of productivity. As the result shows, it is possible for the concrete made with accelerator to get greater durability than the normal combination concrete after it was demold because concrete mixed accelerator showed large enough compressive strength. [1].
\end{abstract}

Index Terms-Accelerator, admixture, concrete lining, hydration, NATM.

\section{INTRODUCTION}

That is represented by lining concreting construct in NATM up to now, targeted for the construction method which does shuttering removal by low strength relatively. The experimental consideration of the purpose which improve the productivity of the concrete construction.

Application of a developed high-early-strength agent has been decided by a new concept. Compression strength $3 \mathrm{~N} / \mathrm{mm}^{2}$ in material age for 10 hours is decided as the numerical target in detail, and inspects about a combination of material to meet its target compression strength [2].

The main ingredient is a nanoparticle of calcium silicate hydrates $(\mathrm{C}-\mathrm{S}-\mathrm{H})$, and acts as a hydration core, and makes them promote a hydration reaction. Concrete possess the new harden accelerator of mechanism which improvement of initial strength development of concrete. The one by which this high-early-strength agent has been developed for precast concrete. When strength development is early and shuttering removal time be early. Productivity improvement in a concrete product factory can be expected by improvement the turnover rate of the mold. A possibility that the thing which becomes compact concrete can also expect durability increase besides the productivity improvement is also

Manuscript received January 6, 2016; revised May 1, 2016.

T. Yokoyama and S. Date are with Course of Civil Engineering, School of Engineering, Tokai University, Japan (e-mail: north.xxx03@gmail.com)

Y. Uno and S. Hashimoto are with the Department of Civil Engineering, Technical Research Institute, Sato Kogyo Co., Ltd., Japan. considered. However, there are no results that applied to tunnel lining concrete construction so far. In addition, confirmation was performed by an effect because neither the quantity of unit cement nor the example and was examined by around $300 \mathrm{~kg} / \mathrm{m}^{3}$ of concrete combination no existed. When construct by the usual cycle without doing shuttering removal (By material age for about 20 hours) early using a high-early-strength agent, it is considered that the durability improves. It was applied to a part section of lining concrete by NATM in actual tunnel construction [3]. The application to the tunnel construction for which ready mixed concrete is used was first time in Japan.

In this paper, the compression strength and coefficient of permeability was measured as the quality after indurating of lining concrete and the result which considered a possibility of the durability increase is described.

\section{METHOD OF EXPERIMENT}

\section{A. Outline of Experiment}

First, now request to maintain the quality of the concrete and to shorten the construction cycle to improve the productivity of the concrete construction. Necessary to early strength development of concrete for it. Up to now, using high-early-strength cement, increase the curing temperature after lining concrete placement, increases the weight of cement in unit volume, or decrease water cement issue much more than to be designed. It's possible to advance strength development, but there is a possibility that the durability is damaged in the long time and crack occurs by the temperature.

It is difficult to make durability increase compatible and productivity improvement by the rapidly construction. On a high-early-strength agent with a developed new harden accelerator of mechanism and added to reduce manufacture cycle in a precast concrete product factory.

It is possible to apply concrete combination with that and achieve securement of early strength and securement of compact pore structure.

\section{B. Inspection at a Fact Site}

To apply concrete combination with a high-early-strength agent to fact tunnel construction, compressive strength test was carried out of young material age for 7 days and for 28 days by the laboratory level first targeted for the application combination. Concrete combination with a high-early-strength agent was used for a part section of lining concrete, NATM and compressive strength test and gas permeability test (torrent) were carried out using material age for 28 days as a target with a selection with other standard 
combination

TABLE I: MATERIALS USED

\begin{tabular}{|c|c|c|}
\hline \multirow{2}{*}{ Cement } & B & $\begin{array}{l}\text { Blast-furnace slag cement } \\
\text { Density } 3.04 \mathrm{~g} / \mathrm{cm}^{3}\end{array}$ \\
\hline & $\mathrm{N}$ & $\begin{array}{l}\text { Ordinary portland cement } \\
\text { Density } 3.16 \mathrm{~g} / \mathrm{cm} 3\end{array}$ \\
\hline \multirow{2}{*}{ Fine aggregate } & S1 & $\begin{array}{l}\text { River sand from } \\
\text { Kyoto yura } \\
\text { Density } 2.56 \mathrm{~g} / \mathrm{cm} 3 \\
\end{array}$ \\
\hline & $\mathrm{S} 2$ & $\begin{array}{l}\text { Crushed sand from Kyoto } \\
\text { kyoutango } \\
2.56 \mathrm{~g} / \mathrm{cm} 3\end{array}$ \\
\hline Coarse Aggregate & G & $\begin{array}{l}\text { Crushed stone from Kameoka } \\
\text { Density } 2.67 \mathrm{~g} / \mathrm{cm}^{3}\end{array}$ \\
\hline \multirow[b]{2}{*}{ Chemical admixture } & HA & $\begin{array}{l}\text { Hyderation accelerator. : } \\
(\mathrm{C}-\mathrm{S}-\mathrm{H})\end{array}$ \\
\hline & WRA & $\begin{array}{l}\text { Water-reducing agent(type of } \\
\text { AE) } \\
: \text { (Lignin sulfonate and } \\
\text { oxycarboxylate) }\end{array}$ \\
\hline
\end{tabular}

\section{1) Materials and mix proportion}

It is one of the methods to realize the safe improvement in the demolding and the prevention of the initial defect to accelerate initial strength development of the lining concrete, in recent tunnel construction. Therefore [4], [5].

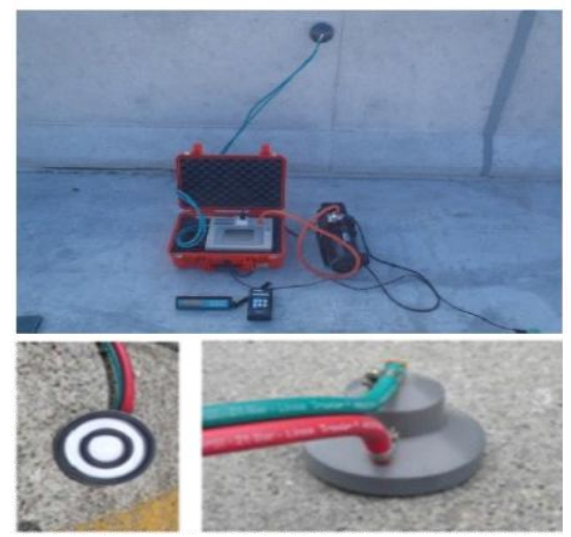

Fig. 1. Gas permeability test device.

From the results of former research [6], Mix design was performed using the same material as the plant where lady mixed concrete is supplied to a tunnel construction site Standard combination of lining concrete is $24-15-40 \mathrm{BB}$, and test mixing concrete is performed, targeting the slump $15 \mathrm{~cm}$. Specified mix proportion was fixed in Table I and Table II [7].

\section{2) Gas permeability test}

Gas permeability test estimates air permeability in a concrete surface part and expresses it in the size of the coefficient of permeability are measured. Compact pore structure is so close that its numerical value is small. The test method put into effect this time is Trent way, made in
Material Advanced Services Ltd. Permea - TORR was used (Fig. 1). It is the system which measures infiltration factor using Szell had 2 piece, the inner chamber and the outside chamber and calculates the numerical value from change of pressure after the inner chamber decompression. It's by decompressing while controlling it by a pulsometer by computer control inside the equipment as the outside chamber will be the same pressure as the inner chamber. A pulsometer decompresses while controlling it as the outside chamber and the inner chamber will be the same pressure. And it's possible to exclude influence in a fragile part in a concrete surface by the outside chamber and estimate the quality of one axis cross sectional direction of the inner chamber (Fig. 2 and Fig. 3) [8].

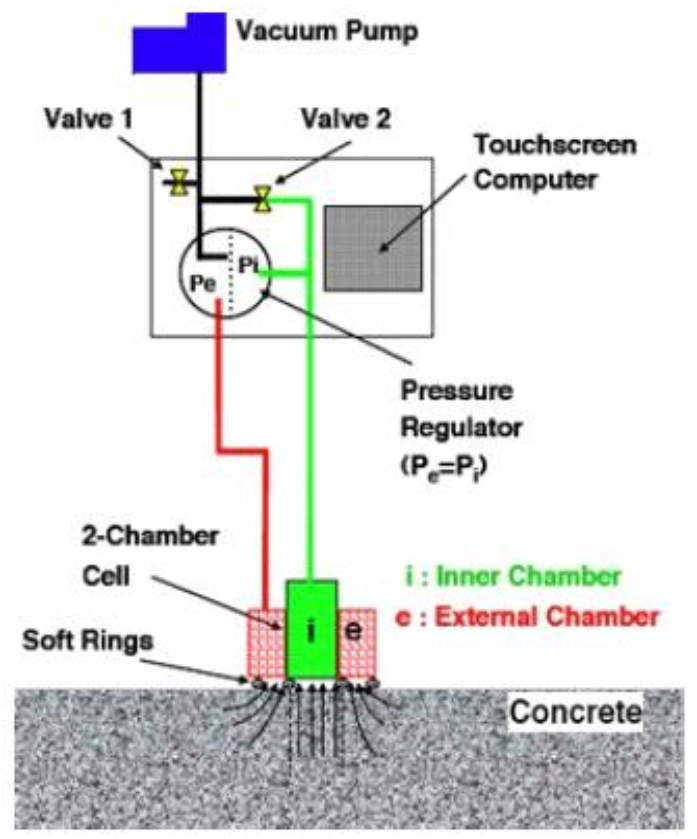

Fig. 2. Concept of gas permeability test.

\section{RESULTS AND DISCUSSION}

\section{A. Compressive Strength Test Result}

A compressive strength test result is indicated in Table 3.

The manufacture and curing of the test specimen that the experiment was conducted in the examination room of the plant maintained environment of $22 \pm 2{ }^{\circ} \mathrm{C}$ [9].

The strength development beyond standard combination of 19 hours later of material age is checked in material age for 10 hours or 11 hours, and concrete combination with a high-early-strength agent reaches the shuttering removal strength. As it can be said surplus strength development, even the material age for 28 does not show strength too much more than standard [10].

TABLE II: MIX PROPORTION

\begin{tabular}{|c|c|c|c|c|c|c|c|c|c|}
\hline \multirow{2}{*}{ Case } & \multirow{2}{*}{$\begin{array}{l}\text { W/C } \\
(\%)\end{array}$} & s/a & \multicolumn{7}{|c|}{ Unit weight $\left(\mathrm{kg} / \mathrm{m}^{3}\right)$} \\
\hline & & $(\%)$ & $\mathrm{W}$ & $\mathrm{C}$ & S1 & S2 & G & WRA & HA \\
\hline $\begin{array}{c}\text { C-S-H } \\
\text { combination }\end{array}$ & \multirow{2}{*}{55} & 42.4 & \multirow{2}{*}{160} & 291 & 617 & 154 & \multirow{2}{*}{1089} & 11.46 & 1.46 \\
\hline Standard combination & & 42 & & 296 & 607 & 152 & & 0 & 2.96 \\
\hline
\end{tabular}


TABLE III: COMPRESSIVE STRENGTH TEST RESUlT

\begin{tabular}{c|c|c|c|c}
\hline \multicolumn{5}{c}{ Compressive strength } \\
\hline 7 hours & 11 hours & 19 hours & 7 day & 28 day \\
\hline $\begin{array}{c}2.90 \\
(\mathrm{~N} / \mathrm{mm} 2)\end{array}$ & $\begin{array}{c}3.47 \\
(\mathrm{~N} / \mathrm{mm} 2)\end{array}$ & - & $\begin{array}{c}31.6 \\
(\mathrm{~N} / \mathrm{mm} 2)\end{array}$ & $\begin{array}{c}40.9 \\
(\mathrm{~N} / \mathrm{mm} 2)\end{array}$ \\
\hline- & - & $\begin{array}{c}2.73 \\
(\mathrm{~N} / \mathrm{mm} 2)\end{array}$ & $\begin{array}{c}17.8 \\
(\mathrm{~N} / \mathrm{mm} 2)\end{array}$ & $\begin{array}{c}28.6 \\
(\mathrm{~N} / \mathrm{mm} 2)\end{array}$ \\
\hline
\end{tabular}

TABLE IV: QUALITY TEST OUTCOME AFTER HARDEN

\begin{tabular}{|c|c|c|}
\hline \multirow{2}{*}{$\begin{array}{l}\text { Compressive strength } \\
(\mathrm{N} / \mathrm{mm} 2)\end{array}$} & \multicolumn{2}{|c|}{ Gas permeability $\left(\times 10^{-16} \mathrm{~m}^{2}\right)$} \\
\hline & Each measure & Average \\
\hline \multirow{3}{*}{$\begin{array}{c}35.8 \\
\text { (age of material Thirty-one ) }\end{array}$} & 0.4 & \multirow{3}{*}{0.32} \\
\hline & 0.32 & \\
\hline & 0.24 & \\
\hline $\begin{array}{c}31.4 \\
\text { (age of material Twenty-nine) }\end{array}$ & 1.3 & 0.96 \\
\hline
\end{tabular}

\section{B. Quality Test Outcome after Harden (Target a Lining Concrete)}

Concrete combination and standard combination with a high-early-strength agent were deposit concrete in an area it neighbors. Material age slipped for 2 days by the difference in deposit concrete days, when estimating the quality after harden, but there are no differences between the material age for 31 days and the material age for 29 days of examination operation. When applying concrete combination with a high-early-strength agent, shuttering removal is performed and construction is performed early. But the strength development which exceeds standard combination in young material age could be confirmation as a result of the test examination room level. There was a change in the situation of the site, and it was no need to have a shuttering removal by material age for 10 hours, and it was for rapidly construction realization using this high-early-strength agent.

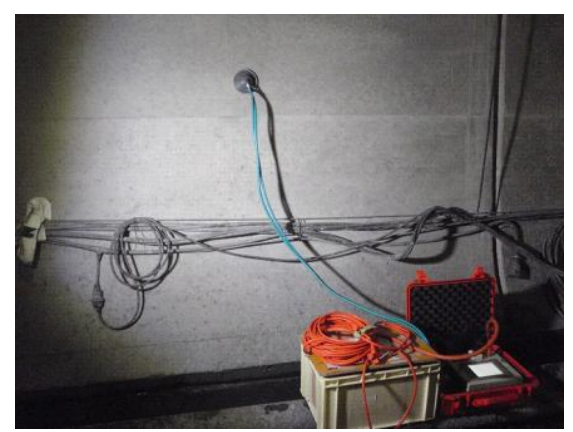

Fig. 4. On site gas permeability test implementation circumstances are indicated.

However, construction with standard cycle were applied for the purpose of a data collection by the fact level this time. Shuttering removal is performed by material age for about 20 hours according to the standard construction cycle, after that, curing were applied as similarly as the BL which made of standard combination and which places next.

On site gas permeabi $k T=\left(\frac{V c}{A}\right) \cdot \frac{u}{2 \varepsilon P_{a}} \cdot\left\lfloor\frac{\operatorname{In} \frac{P_{a}+\Delta P_{i}\left(t_{f}\right)}{P_{a}-\Delta P_{i}\left(t_{f}\right)}}{\sqrt{t_{f}}-\sqrt{t_{0}}}\right\rfloor$
$K T$ : Gas permeability $\left(\mathrm{m}^{2}\right)$

Vc: Sell of inside volume $\left(\mathrm{mm}^{3}\right)$

A: Sell of inside Cross-sectional area $\left(\mathrm{mm}^{3}\right)$

$\mu$ : Air viscosity $\left(=2.0 \times 1.0 \times\right.$ E-SN.s $\left./ \mathrm{m}^{2}\right)$

$\delta$ : Porosity $(=0.15)$

$\mathrm{Pa}$ : Outside pressure $\left(\mathrm{N} / \mathrm{m}^{2}\right)$

$\nabla P_{t}$ : Finish measurement sell of inside compressive $\left(\mathrm{N} / \mathrm{m}^{2}\right)$

$t_{f}$ : Finish measurement time(s) (2-6minute or 12 minute)

$t_{0}$ : measurement time $(=60 \mathrm{~s})$

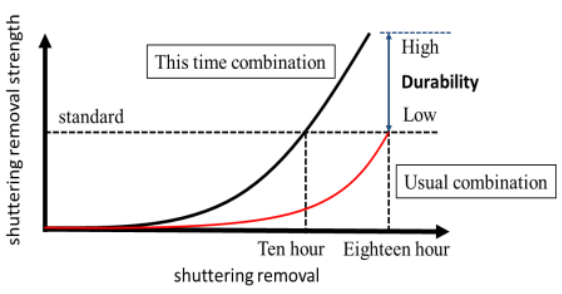

Fig. 5. Effect image.

When applying concrete combination with a high-early-strength agent to the standard construction cycle, it is possible to compact pore structure. I verified whether durable concrete was obtained relatively compared with standard combination.

Quality test outcome after harden is shown in Table 4, and on site gas permeability test implementation circumstances are indicated in Fig 4. Coefficient of gas permeability is about $1 / 3$ compared with standard combination for the concrete combination to which a high-early-strength agent was applied. When it was compared with the general standard and estimate by the absolute value, the grade of "excellent"-"good"-"standard"-"worse"-"very worse" is separated, and $0.1-1.0 \times 10^{-16} \mathrm{~m}^{2}$ is set as "standard"[11]. But when material age and a reaction of hydration developed, coefficient of gas permeability changes, and it is difficult to do the same evaluation by the cure condition and it was enough to estimate relatively with the one of the same care condition this time.

When the pore structure in the stage material age for about 4 weeks has passed is compact relatively, it's also possible to estimate using a high-early-strength agent, and a high thing knows a possibility of the durability increase. It can be said 
that it was possible to make securement of early strength and securement of compact pore structure compatible by this technology [12], [13].

\section{CONCLUSION}

This technology aims at tunnel construction in the study which pursuit productivity improvement of concrete construction, and is the part of the result the process aiming at the high-early-strength shuttering removal of lining concrete and the reduction in construction cycle obtained. In this study, some materials in which an improvement effect of the initial strength development that the cycle time of concrete lining work in NATM can be reduced

The combination of materials that compressive strength of $2.9 \mathrm{~N} / \mathrm{mm}^{2}$ at the age of 7 hours was confirmed.

It is possible that perform a demolding of 1 cycles in a day.

Compressive strength and performance of the concrete to improve security and durability of a dense pore structure is formed early strength can be obtained by using a high early strength agent than usual formulation

As the result shows, it is possible for the concrete made with accelerator to get greater durability than the normal combination concrete after it was demold because concrete mixed accelerator showed large enough compressive strength.

The effect image of this study expects is shown in Fig. 5 [14], [15].

It is expected to advance a study to plan for more compatibility of productivity improvement and durability increase in the future.

Various data collection concerning not only quality but durability at the upcoming construction work from now on is being planned and these data will be reported in the future.

\section{ACKNOWLEDGEMENT}

This research was supported by the BASF JAPAN Corporation and Civil and urban engineering department of Fukuoka University

\section{REFERENCES}

[1] Y. Uno, T. Shiga, and S. Date, "Study about productivity improvement of concrete construction," Sato Kogyo Research Center Report, pp. 1-6, 2014.

[2] T. Yoshikawa, M. Hosokawa, and T. Tanaka, "MgO effect on hydrothermal solidification of blast furnace slag," ISIJ International, vol. 48, no. 5, pp. 557-562, 2008.

[3] K. Nakatani, Y. Uno, and S. S. S. Date, "Study about productivity improvement of concrete construction," in Proc. Collection of Japan Society of Civil Engineering 70st Annual Academic lecture Summaries Six Section, pp. 1217-1218, 2015.

[4] N. Shiga, T. Misaka, H. Uno, and T. Shinomura, "One consideration about the initial strength development of the lining concrete for tunnels," in Proc. Collection of Japan Society of Civil Engineering 69th annual Academic Lecture Summaries Sixth Section, pp. 111-112, 2013.

[5] N. Shiga, T. Misaka, H. Uno, and T. Shinomura, "One consideration about the initial strength development of the lining concrete for tunnels," in Proc. Collection of Japan Society of Civil Engineering 69th Annual Academic Lecture Summaries Sixth Section, pp. 111-112, 2013.
[6] M. Watabe, Y. Uno, and T. Shimomura, "Consideration about combination for lining concrete to which a high-early-strength agent was applied," in Proc. Collection of Japan Society of Civil Engineering 70st Annual Academic Lecture Summaries Six Section, pp. 1313-1314, 2015.

[7] S. Hoshino, K. Yamada, and H. Hirao, "XRD/Rietveld analysis of the hydration and strength development of slag and limestone blended cement," Journal of Advanced Concrete Technology, vol. 4, no.3, pp. 357-367, Oct. 2006

[8] T. Saeki, K. Sasaki, and K. Shinada, "Estimation of chloride diffusion coefficent of concrete using mineral admixtures," Journal of Advanced Concrete Technology, vol. 4, no. 3, pp. 385-394, Oct. 2006.

[9] Y. Luan, T. Ishida, T. Nawa, and T. Sagawa, "Enhanced model and simulation of hydration process of blast furnace slag in blended cement ," Journal of Advanced Concrete Technology, vol. 10, pp. 1-13, 2012.

[10] M. Satou, H. Minagawa, and M. Hisada, Influence of Mineral Admixture on the Hardening Process of Mortar.

[11] H. Ito, I. Maruyama, and R. Sato "Early age defomartion and resultant induced stress in expansive high strength concrete," Journal of Advanced Concrete Technology, vol. 2, no. 2, pp. 155-174, Jun. 2004.

[12] Japan Society of Civil Engineering: Tunnel Concrete Standard Specifications, the Commentary, 2006.

[13] "Japan society of civil engineering, concrete technology series no.97," Symposium Annual Academic Lecture Summaries, p. 142, 2012.

[14] E. Sakai, T. Ansai, D. Atarashi, and Y. Ikeo, "Mterial design of high volume blast furnace slag cement in consideration of early hy daration ofcement," Cement Science and Concrete Technology, no. 65, 2011.

[15] M. Ikeda, C. Hashimoto, Y. Tsuji, and T. Sugiyama, "The influence that good self-care temperature and an early demolding give to initial strength of mortar," in Proc. Collection of Japan Society of Civil Engineering 51st Annual Academic Lecture Summaries Fifth Section, pp. 524-525, 1996

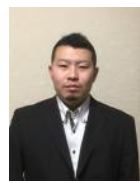

Taiki Yokoyama was born in Iwate Pref, Japan. He was graduated from Tokai University in 2015, Japan. He is a student of Graduate School of Tokai University, Japan. He major field of study is construction materials engineering.

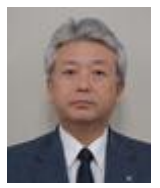

Yoshiki Uno was born in Tokyo Pref, Japan. He was graduated from Waseda University in 1986, a doctor of engineering, Kanazawa Institute of Technology in 2013, Ishikawa Japan. He major field of study is concrete engineering, maintenance engineering. $\mathrm{He}$ is working for Sato Kogyo Co., ltd. as general manager, Department of Civil Engineering, Technical Research Institute, 14-10 Morinosato Aoyama, Atsugi Kanagawa Japan. His current and previous research interests are risk management, maintenance, and prevention technology. Dr. Uno is member of JCI, JSCE

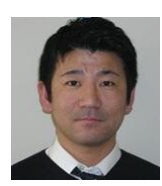

Shin-ichiro Hashimoto was born in Hiroshima Pref, Japan. He was graduated from Maebashi Institute of Technology in 2001, Gumma Japan. a doctor of engineering, Tokushima University in 2006, Tokushima Japan. He major field of study is concrete engineering. He is working for Fukuoka Univ. as assistant professor of Dept. of Civil Engineering, 8-19-1 Nanakuma, Jonan-ku, Fukuoka Japan. His current research interests material design, workability and pumpability of fresh concrete. Dr. Hashimoto is member of JCI, JSCE, AIJ

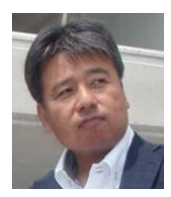

Shigeyuki Date was born in Fukuoka Pref. Japan. He was graduated from Nagasaki University in 1987, a doctor of engineering, Gumma University in 2005, Gumma Japan. He major field of study is concrete engineering, maintenance engineering. He is working for Tokai Univ. as Professor of Dept. of Civil Engineering, 4-1-1 Kitakaname Hiratsuka Kanagawa Japan. His current and previous research interests are material design, durability of concrete structure, concrete production, and pre-cast concrete. Dr. Date is member of JCI, JSCE, AIJ, SMSJ. 